\title{
Apparent Recovery of Duodenal Odd- and Branched-Chain Fatty Acids in Milk of Dairy Cows
}

\author{
R. J. Dewhurst, ${ }^{\star 1,2}$ J. M. Moorby, ${ }^{*}$ B. Vlaeminck, $\dagger$ and V. Fievez† \\ *Institute of Grassland and Environmental Research, Plas Gogerddan, Aberystwyth, SY23 3EB, United Kingdom \\ †Laboratory for Animal Nutrition and Animal Product Quality, Ghent University, Proefhoevestraat 10, 9090 Melle, Belgium
}

\begin{abstract}
This study compared flows of odd- and branchedchain fatty acids (OBCFA) at the duodenum with corresponding yields in milk. Four mid-lactation HolsteinFriesian dairy cows were offered 4 dietary treatments, based on different ratios of ryegrass silage and concentrates $(80: 20,65: 35,50: 50$, and 35:65 on a dry matter basis), in a $4 \times 4$ Latin square design experiment with 4 -wk periods. Samples of milk and duodenal digesta were collected during the final week of each period and analyzed for fatty acids. Biohydrogenation of linoleic and $\alpha$-linolenic acids (C18:2 and C18:3) was extensive for all treatments, with a tendency to be lower for C18:3 with increased concentrate feeding. The proportion of duodenal flows of these fatty acids that appeared in milk declined with increasing concentrate feeding. There was little change in the yield of OBCFA in milk in response to increasing level of concentrate inclusion and no significant relationship with the yield of microbial protein at the duodenum. The efficiency of transfer of iso C15:0 and anteiso C15:0 from the duodenum to milk was similar to that for C18:3, with a reduced proportion transferred into milk at higher flows. Yields of $\mathrm{C} 15: 0, \mathrm{C} 17: 0$, and iso C17:0 in milk were higher than duodenal flows, confirming synthesis in animal tissues. Key words: dairy cow, fatty acids, biohydrogenation, milk composition
\end{abstract}

\section{INTRODUCTION}

Rumen microbial protein is often the main component of MP supply to dairy cows (NRC, 2001). A large number of studies over the last $40 \mathrm{yr}$ have estimated microbial protein flow from the rumen using marker techniques and cannulated animals. Odd- and branched-chain fatty acids (OBCFA) are distinctive components of ru-

Received October 30, 2006

Accepted November 20, 2006.

${ }^{1}$ Corresponding author: dewhursr@lincoln.ac.nz

${ }^{2}$ Current address: Agriculture and Life Sciences Division, Lincoln University, Canterbury, New Zealand. men microorganisms (Harfoot, 1978) and have recently been used as markers of the microbial protein content within rumen and duodenal digesta (Vlaeminck et al., 2005, 2006).

One of the major difficulties when estimating the composition of duodenal flows is obtaining representative samples of microorganisms leaving the rumen. For example, there is relatively little information about the relative proportions of solid- and liquid-associated bacteria in duodenal digesta (Vlaeminck et al., 2006). The relatively constant ratio of OBCFA: $N$ within solid- and liquid-associated bacteria (Vlaeminck et al., 2006) means that OBCFA may be more robust than conventional markers, such as purines (Vlaeminck et al., 2005).

Odd- and branched-chain fatty acids are significant components of milk fat, which has led to speculation that milk OBCFA might provide a noninvasive technique for estimating microbial protein flows from the rumen (Dewhurst et al., 2000). The main OBCFA in milk are isomers of pentadecanoic acid (C15:0, iso $\mathrm{C} 15: 0$, and anteiso $\mathrm{C} 15: 0)$, and heptadecanoic acid (C17:0, iso C17:0, and anteiso C17:0). Although there is some evidence of a useful relationship between milk OBCFA and microbial protein flow from the rumen (Vlaeminck et al., 2005), there has been no robust evaluation of the relationship between OBCFA flowing at the duodenum and their yield in milk.

The objective of this work was to evaluate the relationship between duodenal flows of OBCFA and their yield in milk, for a series of diets differing widely in forage:concentrate ratio.

\section{MATERIALS AND METHODS}

\section{Experimental Design}

The experimental design and feed composition have been described previously (Moorby et al., 2006). All procedures were regulated by the UK Home Office under the Animals (Scientific Procedures) Act of 1986. Briefly, 4 multiparous Holstein-Friesian dairy cows [starting at a mean $90 \mathrm{DIM}(\mathrm{SD}=33.6)$, with simple cannulas 
in the rumen and the proximal duodenum, were used in a $4 \times 4$ Latin square design experiment with 4 -wk periods. Four dietary treatments composed of ryegrass silage and dairy concentrate (NDF, $\mathrm{CP}$, and starch were $24.8,22.8$, and $22.1 \%$ of DM, respectively) were offered at different forage-to-concentrate $(\mathrm{F}: \mathrm{C})$ ratios $(80: 20$, $65: 35,50: 50$, and $35: 65$ on a DM basis). The concentrate comprised (\% as fed): wheat (30), rapeseed meal (15), corn gluten feed (15), linseed meal (12), sunflower meal (11), sugar beet pulp (6), molasses (6), and palm kernel meal (2). Sodium bicarbonate was added to all diets at the rate of approximately $1.7 \%$ of total DM, mixed in with the concentrate ration, which was offered in 2 equal portions per day, 1 at each milking.

\section{Milk and Digesta Sampling}

Cows were milked twice a day, at approximately 0800 and $1600 \mathrm{~h}$, throughout the experiment. Milk samples were taken for fatty acid analysis during the final week of each period. Afternoon and morning milk samples were analyzed separately and composited by day before statistical analysis.

Duodenal digesta was sampled over $2 \mathrm{~d}$ in the final week of each period, as described by Dewhurst et al. (2003). Ytterbium acetate and chromium EDTA were used as particulate and liquid markers, respectively, to allow reconstitution of true digesta composition (Faichney, 1975).

\section{Sample Handling and Fatty Acid Analysis}

Milk, feed, and digesta samples were stored frozen $\left(-18^{\circ} \mathrm{C}\right)$ without preservative. Fatty acid methyl esters (FAME) were prepared from freeze-dried feed and digesta samples using a one-step extraction and methylation procedure (Sukhija and Palmquist, 1988). Analysis of feed and digesta FAME used a 'Select for FAME' column (Varian Ltd., Oxford, UK; $100 \mathrm{~m} \times 0.25 \mathrm{~mm}$ i.d.) on a CP-3800 gas chromatograph (Varian Ltd.). The carrier gas was helium, and detector and injector temperatures were 255 and $250^{\circ} \mathrm{C}$, respectively. Peaks were identified from external standards and quantified using an internal standard (C19:0).

The digesta FAME were run with the following temperature program: hold at $70^{\circ} \mathrm{C}$ for $1 \mathrm{~min}$, increase to $100^{\circ} \mathrm{C}$ at $5^{\circ} \mathrm{C} / \mathrm{min}$, hold for $2 \mathrm{~min}$, increase to $175^{\circ} \mathrm{C}$ at $10^{\circ} \mathrm{C} / \mathrm{min}$, hold for $34 \mathrm{~min}$, increase to $225^{\circ} \mathrm{C}$ at $4^{\circ} \mathrm{C} / \mathrm{min}$, and hold for $20 \mathrm{~min}$. Carrier gas was run at constant pressure with one increase to avoid falling off the Van Deemter plateau: $275 \mathrm{kPa}$ for $52.5 \mathrm{~min}$, increase at 2.75 $\mathrm{kPa} / \mathrm{min}$ to $310 \mathrm{kPa}$, and hold for $20.5 \mathrm{~min}$. This complex temperature and pressure program was used to maximize separation of C18:1 and C18:2 isomers.
Milk fat from thawed milk was extracted in 3 steps according to Vlaeminck et al. (2005). In the first step, samples were extracted with ammonium hydroxide solution, ethanol, diethyl ether, and petroleum ether. In the second step, samples were extracted with ethanol, diethyl ether, and petroleum ether; in the final step, only diethyl ether and petroleum ether were used. Extracts were combined and brought up to a final volume of $20 \mathrm{~mL}$ with a mixture of diethyl ether and petroleum ether $(1: 1, \mathrm{vol} / \mathrm{vol})$. Fatty acids were methylated and analyzed by gas chromatography on a Hewlett-Packard 6890 gas chromatograph (Hewlett-Packard Co., Brussels, Belgium) with a CP-Sil88 column for FAME (100 $\mathrm{m} \times 0.25 \mathrm{~mm} \times 0.2 \mu \mathrm{m}$; Chrompak Inc., Middelburg, the Netherlands) as described by Vlaeminck et al. (2005). We were unable to resolve anteiso C17:0 with confidence from $\mathrm{C} 16: 1$ and so results are not presented for these fatty acids.

\section{Statistical Analysis}

Results were analyzed using the Genstat 7 software package (Release 7.1, 2003; Lawes Agricultural Trust, Rothamsted, UK). The ANOVA model used a treatment structure of $\mathrm{F}: \mathrm{C}$ ratio (which was partitioned into linear, quadratic, and other effects; $3 \mathrm{df}$ ), and a blocking structure of period + cow ( $3 \mathrm{df}$ each). There were $15 \mathrm{df}$ in total ( 4 cows $\times 4$ periods), and so 6 residual df. Statistical significance was declared at the $95 \%$ confidence level, although trends (90\% confidence level) were also noted.

\section{RESULTS}

Results for feed intake, milk production and composition, rumen function, rumen and total tract digestion, and nitrogen partitioning have been presented previously (Moorby et al., 2006). Rumen ammonia concentration increased significantly with increasing concentrate feeding, but there was no significant effect on rumen $\mathrm{pH}$, and significant changes in acetate molar percentage (decrease) and butyrate molar percentage (increase) were numerically small.

Concentrations of the major fatty acids in the feeds used in this study are presented in Table 1. Linoleic, oleic, and palmitic acids were the predominant fatty acids in the concentrate, with lower levels of $\alpha$-linolenic acid supplied by the linseed meal. The total level of fatty acid, as well as the proportion of C18:3 fatty acid (45\%), was at the lower end of the usual range for ryegrass silage. Odd- and branched-chain fatty acid comprised only 1.13 and $0.27 \%$ of the total fatty acids in the grass silage and concentrates, respectively.

Duodenal flows of individual fatty acids are presented in Table 2. There was a substantial increase (approxi- 
Table 1. Concentrations of odd- and branched-chain fatty acids and other significant fatty acids in the feeds used in the experiment (g/ $\mathrm{kg}$ of DM)

\begin{tabular}{lcc}
\hline Fatty acid & Grass silage & Concentrates \\
\hline C4:0 & 0.378 & 0.018 \\
C6:0 & 0.088 & 0.054 \\
C8:0 & 0.012 & 0.176 \\
C10:0 & 0.004 & 0.160 \\
C12:0 & 0.046 & 2.07 \\
C14:0 & 0.116 & 0.788 \\
Iso C15:0 & 0.013 & 0.006 \\
Anteiso C15:0 & 0.039 & 0.014 \\
C15:0 & 0.031 & 0.036 \\
C16:0 & 2.78 & 7.28 \\
C16:1 & 0.075 & 0.166 \\
Iso C17:0 & 0.010 & 0.006 \\
Anteiso C17:0 & 0.011 & 0.007 \\
C17:0 & 0.035 & 0.047 \\
C18:0 & 0.313 & 1.410 \\
C18:1 & 0.503 & 13.02 \\
C18:2 & 2.19 & 15.29 \\
C18:3 & 5.52 & 2.29 \\
Total fatty acids & 12.3 & 43.2 \\
\hline
\end{tabular}

mately 75\%) in the duodenal flow of anteiso C15:0 with increasing concentrate proportion, and smaller increases (10 to 35\%) for other OBCFA apart from C15:0 (for which the level was similar across F:C ratios). Biohydrogenation values were calculated as the loss of the fatty acid of interest between the diet and duodenal flow as a percentage of the intake of the fatty acid. There was no significant effect of $\mathrm{F}: \mathrm{C}$ ratio on biohydrogenation of C18:2 (mean $=90.5 \%)$, but a tendency $(P<$ 0.1 ) for biohydrogenation of $\mathrm{C} 18: 3$ to reduce with in- creasing concentrate feeding $(95.0,94.1,92.8$, and 93.3\%; SED = 0.77).

Daily yields of individual fatty acids in milk are presented in Table 3. The proportions of major fatty acids $(\mathrm{C} 14: 0=10.5 \% ; \mathrm{C} 16: 0=30.3 \% ; \mathrm{C} 18: 0=9.8 \% ; \mathrm{C} 18: 1=$ $20.4 \%$ ) were well within normal ranges (Jensen, 2002). Total milk fatty acids are those reported in Table 3 as well as low levels of other C18:1 isomers, C20 and C22 fatty acids (19 different peaks, which together made up $2.3 \%$ of total fatty acids). Levels of C18:3 in milk ( $0.33 \%)$ were in the normal range for cows fed silage and concentrates (Dewhurst and Lee, 2005), whereas levels of conjugated linoleic acid (cis-9, trans-11;0.70\%) were at the upper end of the range for cows fed silage-based diets. Odd- and branched-chain fatty acids made up only a small percentage of milk fatty acids: $\mathrm{C} 15: 0=1.23 \%$; iso $\mathrm{C} 15: 0=0.27 \%$; anteiso $\mathrm{C} 15: 0=0.46 \% ; \mathrm{C} 17: 0=0.57 \%$; iso $\mathrm{C} 17: 0=0.21 \%$; and $\mathrm{C} 17: 1=0.28 \%$.

Figure 1 shows the relationship between duodenal flows and yields in milk for each OBCFA (and C18:3 for comparison), by treatment mean. It is immediately apparent that there were not strong relationships between duodenal flows and yields in milk for individual fatty acids. Furthermore, yields of some of the OBCFA in milk were greater than corresponding flows at the duodenum. Table 4 presents these results in terms of the apparent recovery of duodenal OBCFA in milk.

\section{DISCUSSION}

The relatively low level of total fatty acids and the low proportion of $\alpha$-linolenic acid in the grass silage

Table 2. Effects of dietary forage:concentrate ratio on flows $(\mathrm{g} / \mathrm{d})$ of major fatty acids at the duodenum of lactating dairy cows

\begin{tabular}{|c|c|c|c|c|c|c|c|}
\hline \multirow[b]{2}{*}{ Fatty acid } & \multicolumn{4}{|c|}{ Forage:concentrate ratio } & \multirow[b]{2}{*}{ SED } & \multicolumn{2}{|c|}{ Significance $^{1}$} \\
\hline & $80: 20$ & $65: 35$ & $50: 50$ & $35: 65$ & & Linear & Quadratic \\
\hline C8:0 & 0.436 & 0.547 & 0.634 & 0.572 & 0.0674 & $\dagger$ & NS \\
\hline $\mathrm{C} 10: 0$ & 0.370 & 0.418 & 0.533 & 0.469 & 0.0462 & $*$ & NS \\
\hline C12:0 & 1.24 & 1.80 & 3.14 & 3.36 & 0.246 & $* * *$ & NS \\
\hline C14:0 & 3.57 & 4.67 & 6.24 & 6.35 & 0.213 & $* * *$ & $*$ \\
\hline Iso $\mathrm{C} 15: 0$ & 2.57 & 3.05 & 3.49 & 3.41 & 0.144 & $* * *$ & $*$ \\
\hline Anteiso C15:0 & 4.50 & 5.32 & 6.80 & 6.47 & 0.221 & $* * *$ & $*$ \\
\hline C15:0 & 6.24 & 6.56 & 6.68 & 6.12 & 0.132 & NS & $* *$ \\
\hline C16:0 & 43.0 & 58.3 & 83.4 & 87.5 & 2.76 & $* * *$ & $*$ \\
\hline Iso $\mathrm{C} 17: 0$ & 1.14 & 1.31 & 1.42 & 1.44 & 0.0546 & $* *$ & NS \\
\hline C17:0 & 2.45 & 2.54 & 2.86 & 2.73 & 0.035 & $* * *$ & $* *$ \\
\hline C18:0 & 140.6 & 191.8 & 272.1 & 275.4 & 9.84 & $* * *$ & $*$ \\
\hline C18:1 trans- 11 & 12.3 & 16.5 & 21.9 & 25.0 & 1.19 & $* * *$ & NS \\
\hline C18:1 cis-9 & 8.2 & 14.3 & 25.4 & 32.0 & 3.73 & $* * *$ & NS \\
\hline C18:1 cis-11 & 1.34 & 2.18 & 3.81 & 4.30 & 0.305 & $* * *$ & NS \\
\hline C18:2 & 5.19 & 9.43 & 18.39 & 21.24 & 2.655 & $* * *$ & NS \\
\hline C18:3 & 3.08 & 3.93 & 4.99 & 4.71 & 0.436 & $* *$ & NS \\
\hline CLA $^{2}$ cis -9 , trans -11 & 0.078 & 0.144 & 0.189 & 0.234 & 0.0405 & $* *$ & NS \\
\hline CLA trans -10, cis -12 & 0.092 & 0.100 & 0.142 & 0.162 & 0.0409 & $\dagger$ & NS \\
\hline
\end{tabular}

${ }^{1}$ Significance of linear and quadratic treatment effects: $\dagger P<0.1 ; * P<0.05 ; * * P<0.01 ; * * * P<0.001$.

${ }^{2} \mathrm{CLA}=$ conjugated linoleic acid. 
Table 3. Effects of dietary forage:concentrate ratio on yields (g/d) of major fatty acids in milk

\begin{tabular}{|c|c|c|c|c|c|c|c|}
\hline \multirow[b]{2}{*}{ Fatty acid } & \multicolumn{4}{|c|}{ Forage:concentrate ratio } & \multirow[b]{2}{*}{ SED } & \multicolumn{2}{|c|}{ Significance $^{1}$} \\
\hline & $80: 20$ & $65: 35$ & $50: 50$ & $35: 65$ & & Linear & Quadratic \\
\hline $\mathrm{C} 4: 0$ & 27.4 & 31.1 & 32.3 & 37.9 & 2.02 & ** & NS \\
\hline C6:0 & 18.3 & 21.1 & 22.6 & 25.8 & 1.44 & $* *$ & NS \\
\hline C8:0 & 9.35 & 10.40 & 11.54 & 13.10 & 0.880 & $* *$ & NS \\
\hline C10:0 & 17.3 & 20.8 & 23.0 & 25.6 & 1.99 & $* *$ & NS \\
\hline $\mathrm{C} 12: 0$ & 16.9 & 19.4 & 21.8 & 24.2 & 2.33 & $*$ & NS \\
\hline Iso C13:0 & 0.187 & 0.200 & 0.227 & 0.274 & 0.0288 & * & NS \\
\hline Anteiso C13:0 & 0.502 & 0.542 & 0.618 & 0.693 & 0.0851 & $\dagger$ & NS \\
\hline Iso C14:0 & 0.704 & 0.657 & 0.715 & 0.694 & 0.0738 & NS & NS \\
\hline C14:0 & 69.7 & 77.8 & 82.0 & 88.4 & 4.84 & $* *$ & NS \\
\hline C14:1 & 8.24 & 8.35 & 9.05 & 9.69 & 0.841 & NS & NS \\
\hline Iso C15:0 & 2.09 & 2.09 & 2.03 & 1.95 & 0.190 & NS & NS \\
\hline Anteiso C15:0 & 3.27 & 3.43 & 3.58 & 3.61 & 0.339 & NS & NS \\
\hline C15:0 & 9.88 & 9.38 & 8.78 & 8.72 & 0.942 & NS & NS \\
\hline Iso C16:0 & 1.28 & 1.35 & 1.56 & 1.65 & 0.0952 & $* *$ & NS \\
\hline C16:0 & 222 & 237 & 225 & 231 & 11.03 & NS & NS \\
\hline Iso C17:0 & 1.44 & 1.51 & 1.41 & 1.65 & 0.174 & NS & NS \\
\hline C17:0 & 4.45 & 4.35 & 4.01 & 4.18 & 0.232 & NS & NS \\
\hline $\mathrm{C} 17: 1$ & 2.43 & 2.19 & 1.76 & 2.03 & 0.231 & $\dagger$ & NS \\
\hline C18:0 & 57.9 & 72.0 & 79.7 & 87.0 & 2.21 & $* * *$ & $\dagger$ \\
\hline $\mathrm{C} 18: 1$ trans $-6-8^{2}$ & 0.823 & 1.197 & 1.557 & 2.161 & 0.163 & $* * *$ & NS \\
\hline C18:1 trans -9 & 1.04 & 1.30 & 1.65 & 2.23 & 0.189 & *** & NS \\
\hline $\mathrm{C} 18: 1$ trans -10 & 4.25 & 4.98 & 5.82 & 6.57 & 0.433 & **** & NS \\
\hline C18:1 trans -11 & 5.19 & 6.54 & 7.90 & 10.98 & 1.36 & $* *$ & NS \\
\hline C18:1 cis-9 & 129 & 148 & 155 & 182 & 11.10 & $* *$ & NS \\
\hline C18:1 cis-11 & 1.85 & 2.13 & 2.74 & 3.47 & 0.311 & $* * *$ & NS \\
\hline C18:2 & 5.68 & 6.78 & 9.64 & 13.48 & 1.60 & $* *$ & NS \\
\hline CLA $^{3}$ cis -9, trans -11 & 4.38 & 4.81 & 5.46 & 6.80 & 0.451 & $* * *$ & NS \\
\hline CLA trans -10, cis- 12 & 0.413 & 0.269 & 0.184 & 0.127 & 0.0639 & $* *$ & NS \\
\hline C18:3 & 2.27 & 2.41 & 2.61 & 2.97 & 0.231 & $*$ & NS \\
\hline C20:0 & 1.04 & 1.26 & 1.32 & 1.34 & 0.052 & $* *$ & $*$ \\
\hline C20:1 & 1.04 & 1.11 & 1.24 & 1.32 & 0.127 & $\dagger$ & NS \\
\hline
\end{tabular}

${ }^{1}$ Significance of linear and quadratic treatment effects: $\dagger P<0.1 ; * P<0.05 ; * * P<0.01 ; * * * P<0.001$.

${ }^{2}$ Sum of trans-6, trans-7, and trans-8 C18:1, which coeluted.

${ }^{3} \mathrm{CLA}=$ conjugated linoleic acid.

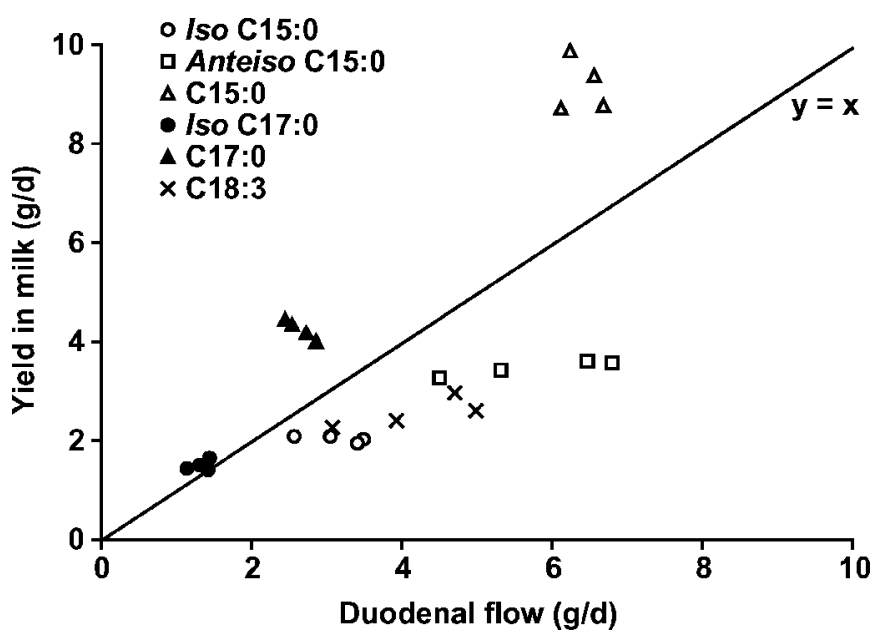

Figure 1. Relationship between flow at the duodenum and yield in milk for individual odd- and branched-chain fatty acids, as well as $\alpha$-linolenic acid. Treatment means are based on 4 animals per treatment and represent forage:concentrate ratios of 20:80, 35:65, 50:50, and 65:35 (DM basis).
(Table 1) reflect the relatively advanced stage of maturity (Dewhurst et al., 2001), which is also reflected in its high NDF content.

\section{Fatty Acid Biohydrogenation}

Biohydrogenation of C18:2 and C18:3 was much more extensive in the current study than in the studies of Kalscheur et al. (1997) and Loor et al. (2004). It is not possible to assign causes for this difference, although it may be a feature of the different forages used in these studies (grass silage vs. grass hay or corn silage and alfalfa haylage; Chilliard et al., 2000).

The tendency for a decrease in biohydrogenation, particularly for C18:3, with increasing concentrate proportion is consistent with, but not as dramatic as, earlier results (Kalscheur et al., 1997; Loor et al., 2004). However, the fact that differences in biohydrogenation were so small, despite a 5-fold range of dietary starch supply (Moorby et al., 2006), does not support the suggestion of Loor et al. (2004) that starch supply has an important direct effect on biohydrogenation. Indeed, neither ru- 
Table 4. Effects of dietary forage:concentrate ratio on apparent recoveries (\%) of duodenal odd- and branchedchain fatty acids in milk

\begin{tabular}{|c|c|c|c|c|c|c|c|}
\hline \multirow[b]{2}{*}{ Fatty acid } & \multicolumn{4}{|c|}{ Forage:concentrate ratio } & \multirow[b]{2}{*}{ SED } & \multicolumn{2}{|c|}{ Significance $^{1}$} \\
\hline & $80: 20$ & $65: 35$ & $50: 50$ & $35: 65$ & & Linear & Quadratic \\
\hline Iso C15:0 & 81.2 & 69.5 & 59.0 & 59.3 & 5.72 & $* *$ & NS \\
\hline Anteiso C15:0 & 72.1 & 64.5 & 53.1 & 56.1 & 6.16 & $*$ & NS \\
\hline $\mathrm{C} 15: 0$ & 159.9 & 143.3 & 133.7 & 144.7 & 14.02 & NS & NS \\
\hline Iso $\mathrm{C} 17: 0$ & 127.5 & 121.6 & 102.6 & 122.9 & 14.82 & NS & NS \\
\hline $\mathrm{C} 17: 0$ and $\mathrm{C} 17: 1$ & 284.8 & 265.8 & 206.0 & 236.2 & 14.95 & $* *$ & $\dagger$ \\
\hline C18:1 trans -11 & 41.5 & 42.9 & 37.1 & 44.6 & 3.92 & NS & NS \\
\hline C18:2 & 107.2 & 74.8 & 54.4 & 62.4 & 8.91 & $* *$ & * \\
\hline C18:3 & 74.0 & 63.5 & 53.0 & 66.0 & 5.20 & $\dagger$ & * \\
\hline
\end{tabular}

${ }^{1}$ Significance of linear and quadratic treatment effects: $\dagger P<0.1 ; * P<0.05$; ** $P<0.01$.

men $\mathrm{pH}$ nor dietary starch supply provided a consistent explanation for effects of $\mathrm{F}: \mathrm{C}$ ratio and buffers on milk fat yield across these studies. The proportion of duodenal flows of $\mathrm{C} 18: 2$ and $\mathrm{C} 18: 3$ that appeared in milk declined with increasing flows of these fatty acids, in agreement with previous work (Chilliard et al., 2000).

\section{OBCFA}

There was little change in the yield of OBCFA in milk in response to increasing levels of concentrate inclusion. This was in contrast to highly significant effects on yields of even-chain fatty acids, including short- and medium-chain de novo synthesized fatty acids and many of those derived from dietary 18-carbon fatty acids. This lack of relationship was surprising, because there was a substantial increase in microbial yield at the duodenum in response to increasing concentrates (Moorby et al., 2006). Nonetheless, there was a strong correlation between the flows of purine bases and of OBCFA in duodenal digesta in this study (Vlaeminck et al., 2006). This suggests that, in contrast to the results of Vlaeminck et al. (2005), milk OBCFA are not useful microbial markers.

There are a number of possible explanations for the differences in the apparent transfer of OBCFA from duodenum into milk. It is possible that treatment differences in mobilization of body fat reserves could contribute to milk OBCFA. However, these cows were studied after peak lactation and the cows were gaining body reserves (Moorby et al., 2006). It is more likely that these effects relate to differences in synthesis and oxidation of fatty acids in cow tissues. As noted above, Chilliard et al. (2000) showed a decreasing transfer of duodenal fatty acids into milk with increasing duodenal flows of fatty acids. This may relate to changes in patterns of fatty acid oxidation, differential incorporation of OBCFA into body fat reserves, or other factors. Interestingly, iso C15:0 and anteiso C15:0 behaved in a very similar way to C18:3, with similar transfer efficiencies and corresponding declines in apparent recoveries from duodenum to milk with increasing concentrate feeding level (Table 4). This is consistent with the decrease in fatty acid oxidation with increasing chain length and increase with increasing unsaturation noted by DeLany et al. (2000).

Yields of C15:0, C17:0, and iso C17:0 fatty acids in milk exceeded duodenal flows substantially (Figure 1 and Table 4). Comparison of the ratios of C15:0 to anteiso C15:0 fatty acids in jugular plasma (0.94) and milk fat (1.99) in the study of Loor et al. (2005) also suggests a relative increase in C15:0 fatty acid in milk, although there was no corresponding increase for C17:0. Earlier studies have shown that the straight-chain fatty acids (C15:0 and C17:0) can be synthesized de novo from propionate (Scaife et al., 1978; Massart-Leën et al., 1983; Rigout et al., 2003). Rigout et al. (2003) showed a relatively smaller response in C17:0 than C15:0 when infusing propionic acid into the rumen, perhaps reflecting a more limited ability to elongate C15:0 to C17:0, although desaturation of C17:0 to C17:1 might also have reduced the apparent effect (Fievez et al., 2003).

There was no evidence for increased synthesis of OBCFA in the mammary gland with increased concentrate feeding, which may reflect the fact (Moorby et al., 2006) that the high-starch diet in this study did not elicit the very high levels of propionate production of the studies by Scaife et al. (1978), or differences in species and metabolic state. It is possible that there were counterbalancing effects of $\mathrm{F}: \mathrm{C}$ ratio, with both synthesis and oxidation of these OBCFA changing with increased concentrate feeding level.

\section{CONCLUSIONS}

There was no significant relationship between the duodenal flow of OBCFA and their yield in milk. The efficiency of transfer of iso C15:0 and anteiso C15:0 from duodenum to milk was similar to that for C18:3, with 
a reduced proportion transferred into milk at higher flows. Yields of C15:0, C17:0, and iso C17:0 in milk were greater than duodenal flows, suggesting de novo synthesis in animal tissues. It is not possible to determine whether the lack of apparent diet effect on duodenum to milk recovery for $\mathrm{C} 15: 0$ and iso $\mathrm{C} 17: 0$ is masked by increased tissue synthesis of these fatty acids with increased concentrate feeding.

\section{ACKNOWLEDGMENTS}

We wish to thank L. J. Davies and V. J. Theobald for care of the animals, and J. K. S. Tweed for analysis of samples. This work was funded by the UK Ministry of Agriculture, Fisheries and Food (now Department for Environment, Food and Rural Affairs).

\section{REFERENCES}

Chilliard, Y., A. Ferlay, R. M. Mansbridge, and M. Doreau. 2000. Ruminant milk fat plasticity: Nutritional control of saturated, polyunsaturated, trans and conjugated fatty acids. Ann. Zootech. 49:181-205.

DeLany, J. P., M. M. Windhauser, C. M. Champagne, and G. A. Bray. 2000. Differential oxidation of individual dietary fatty acids in humans. Am. J. Clin. Nutr. 72:905-911.

Dewhurst, R. J., D. R. Davies, and R. J. Merry. 2000. Microbial protein supply from the rumen. Anim. Feed Sci. Technol. 85:1-21.

Dewhurst, R. J., R. T. Evans, N. D. Scollan, J. M. Moorby, R. J. Merry, and R. J. Wilkins. 2003. Comparison of grass and legume silages for milk production. 2 . In vivo and in sacco evaluations of rumen function. J. Dairy Sci. 86:2598-2611.

Dewhurst, R. J., and M. R. F. Lee. 2005. Alternative strategies for manipulating milk fat in dairy cows. Pages 255-275 in Recent Advances in Animal Nutrition. P. C. Garnsworthy, ed. Nottingham University Press, Nottingham, UK.

Dewhurst, R. J., N. D. Scollan, S. J. Youell, J. K. S. Tweed, and M. O. Humphreys. 2001. Influence of species, cutting date and cutting interval on the fatty acid composition of grasses. Grass Forage Sci. 56:68-74

Faichney, G. J. 1975. The use of markers to partition digestion within the gastrointestinal tract of ruminants. Pages 177-291 in Digestion and Metabolism in the Ruminant. I. W. McDonald and A. C. I. Warner, ed. University of New England, Armidale, Australia.
Fievez, V., B. Vlaeminck, M. S. Dhanoa, and R. J. Dewhurst. 2003. Use of principal component analysis to investigate the origin of heptadecenoic and conjugated linoleic acids in milk. J. Dairy Sci. 86:4047-4053.

Harfoot, C. G. 1978. Lipid metabolism in the rumen. Prog. Lipid Res. $17: 21-54$

Jensen, R. G. 2002. The composition of bovine milk lipids: January 1995 to December 2000. J. Dairy Sci. 85:295-350.

Kalscheur, K. F., B. B. Teeter, L. S. Piperova, and R. A. Erdman. 1997. Effect of forage concentration and buffer addition on duodenal flow of trans-C18:1 fatty acids and milk fat production in dairy cows. J. Dairy Sci. 80:2104-2114.

Loor, J. J., A. Ferlay, A. Oillier, M. Doreau, and Y. Chilliard. 2005. Relationship among trans and conjugated fatty acids and bovine milk fat yield due to dietary concentrate and linseed oil. J. Dairy Sci. 88:726-740.

Loor, J. J., K. Ueda, A. Ferlay, Y. Chilliard, and M. Doreau. 2004. Biohydrogenation, duodenal flow, and intestinal digestibility of trans fatty acids and conjugated linoleic acids in response to dietary forage:concentrate ratio and linseed oil in dairy cows. J. Dairy Sci. 87:2472-2485.

Massart-Leën, A. M., E. Roets, G. Peeters, and R. Verbeke. 1983. Propionate for fatty acid synthesis by the mammary gland of the lactating goat. J. Dairy Sci. 66:1445-1454.

Moorby, J. M., R. J. Dewhurst, R. T. Evans, and J. Danelón. 2006. Effects of dairy cow diet forage proportion on duodenal nutrient supply and urinary purine derivative excretion. J. Dairy Sci. 89:3552-3562.

NRC. 2001. Nutrient Requirements of Dairy Cattle. 7th ed. National Academy Press, Washington, DC.

Rigout, S., C. Hurtaud, S. Lemosquet, A. Bach, and H. Rulquin. 2003. Lactation effects of propionic acid and duodenal glucose in cows. J. Dairy Sci. 86:243-253.

Scaife, J. R., K. W. J. Wahle, and G. A. Garton. 1978. Utilization of methylmalonate for the synthesis of branched-chain fatty acids by preparations of chicken liver and sheep adipose tissue. Biochem. J. 176:799-804.

Sukhija, P. S., and D. L. Palmquist. 1988. Rapid method for determination of total fatty acid content and composition of feedstuffs and feces. J. Agric. Food Chem. 36:1202-1206.

Vlaeminck, B., R. J. Dewhurst, and V. Fievez. 2006. Effect of choice of microbial marker and variation in solid- to liquid-associated bacteria proportion in duodenal contents on the estimation of duodenal bacterial nitrogen flow. J. Dairy Sci. 89(Suppl. 1):360. (Abstr.)

Vlaeminck, B., C. Dufour, A. M. van Vuuren, A. R. J. Cabrita, R. J. Dewhurst, D. Demeyer, and V. Fievez. 2005. Use of odd and branched-chain fatty acids in rumen contents and milk as a potential microbial marker. J. Dairy Sci. 88:1031-1042. 